\title{
A Study on Subfertile Women Suffering from Polycystic Ovarian Syndrome with Hyperprolactinaemia and Hypothyroidism as Associated Factors
} SA ANWARY ${ }^{\mathrm{a}}$, S CHOWDHURY ${ }^{\mathrm{b}}$, P FATIMA $^{\mathrm{c}}$, M ALFAZZAMAN $^{\mathrm{d}}, \mathrm{N}^{\text {BEGUM }}{ }^{\mathrm{e}}$, J BANU ${ }^{\mathrm{f}}$

\section{Summary:}

Objective: This study tried to evaluate association of other factors of subfertility in women suffering from polycystic ovarian syndrome (PCOS).

Methods: Fifty subfertile women suffering from PCOS attending infertility unit of the Department of Obstetrics and Gynaecology, Bangabandhu Sheikh Mujib Medical University (BSMMU), Dhaka, during July 2010 and June 2011, were evaluated.

Results: In out study, Age, BMI and duration of marriage range was 2038 years, $17.7033 .20 \mathrm{~kg} / \mathrm{m}^{2}$ and 116 years,

Introduction:

The polycystic ovary syndrome (PCOS) is one of the most common cause of infertility due to anovulation. The prevalence is estimated to be between 5 to $10 \%{ }^{1}$. The PCOS is a heterogenous condition which is defined by the presence of two out of the three following criteria: (1) oligo and/or anovulation, (2) hyperandrogenism (clinical and/or biochemical) and (3) polycystic ovaries, with the exclusion of other aetiologies ${ }^{2}$. According to

a. Dr. Shaheen Ara Anwary, FCPS, MS (Obs \& Gyn), Assistant Professor, Department of Obstetrics and Gynaecology, Bangabandhu Sheikh Mujib Medical University, Dhaka

b. Dr. Shiuly Chowdhury, FCPS (Obs \& Gyn), Assistant Professor, Department of Obstetrics and Gynaecology, Bangabandhu Sheikh Mujib Medical University, Dhaka

c. Prof. Parveen Fatima, FCPS (Obs \& Gyn), MS (Reprod. Med.), Professor and Head, Infertility Unit, Department of Obstetrics and Gynaecology, Bangabandhu Sheikh Mujib Medical University, Dhaka

d Dr. Md. Alfazzaman, PhD (Surgery), Assistant Professor, Department of Surgery, Z.H. Sikder Women's Medical College and Hospital, Dhaka

e. Dr. Nurjahan Begum, FCPS (Obs \& Gyn), Assistant Professor, Department of Obstetrics and Gynaecology, Bangabandhu Sheikh Mujib Medical University, Dhaka

f. Dr. Jesmin Banu, MS (Obs \& Gyn), Associate Professor, Infertility Unit, Department of Obstetrics and Gynaecology, Bangabandhu Sheikh Mujib Medical University, Dhaka

Address of Correspondence: Dr. Shaheen Ara Anwary, Dom Inno Eldorado, 6/7 Shegun Bagicha, Flat No. A 10, Dhaka 1000, Phone: Mobile 01718271719,01715043612

Received: 8 January, 2013

Accepted: 18 June, 2013 respectively. Serum FSH was normal (1.0 10.0 mIU/ml) in all 50 (100\%) women. Hyperprolactinaemia (serum prolactin $>25 \mathrm{ng} / \mathrm{ml}$ ) was seen in $60 \%$. Hypothyroidism (serum $\mathrm{TSH}>4 \mathrm{iIU} / \mathrm{ml}$ ) was seen in $74 \%$ women. Serum $\mathrm{LH}(>10 \mathrm{mIU} / \mathrm{ml})$ was raised in $74 \%$. USG finding of lower abdomen was abnormal in $75 \%$ cases.

Conclusion: This study concludes that hyperprolactinaemia and subclinical hypothyroidism were associated causes of subfertility other than PCOS.

Key words: PCOS, Subfertility.

(J Banagladesh Coll Phys Surg 2013; 31: 140-143)

the National Institute of Health (NIH), USA, basic diagnostic criteria should be the presence of hyperandrogenism and chronic oligoanovulation, with the exclusion of other causes of hyperandrogenism, such as adult onset congenital adrenal hyperplasia, hyperprolactinaemia and androgen secreting neoplasms ${ }^{3}$. A consensus conference held in Rotterdam agree on the appropriateness of including ultrasound morphology of the ovaries as a further potential criteria to define the PCOS but also established that at least two of the following criteria are sufficient for the diagnosis: oligo and/or anovulation, clinical and/or biochemical signs of hyperandrogenism and polycystic ovaries at ultrasound ${ }^{4}$. The pathophysiology of PCOS may have a genetic component although it can be suggested that the main factors responsible for the increasing prevalence of PCOS are related to the influence of the environment, including dietary habits, behaviour and other still undefined factors ${ }^{1}$.

A baseline assessment of the endocrine status should include measurements of serum prolactin and gonadotropin concentrations and an assessment of thyroid function. Prolactin levels may be elevated in response to a number of conditions, including stress, a recent breast examination, or even having a venipuncture. The elevation, however, is moderate and transient. A more permanent, but still moderate elevation (greater than $700 \mathrm{mIU} / \mathrm{L}$ ) is associated with 
hypothyroidism and is also a common finding in women with PCOS, where prolactin levels up to $2500 \mathrm{mIU} / \mathrm{L}$ have been reported ${ }^{5}$.

The present study was carried out to evaluate association of hyperprolactinaemia and hypothyroidism as other factors of subfertility in patients diagnosed as having PCOS who attended the outpatient department of infertility at Bangabandhu Sheikh Mujib Medical University, Dhaka.

\section{Materials and Methods:}

The study was carried out at the infertility unit of the Department of Obstetrics and Gynaecology, Bangabandhu Sheikh Mujib Medical University (BSMMU), Dhaka, during July 2010 and June 2011, on 50 primary and secondary subfertile women suffering from PCOS. Inclusion criteria: Women suffering from primary and secondary subfertility with PCOS. Exclusion criteria: Women suffering from PCOS with PID, endometriosis and tuberculosis. Approval for the study was obtained from the institution and informed written consents were obtained from all study subjects.

The collected data included age, menstrual history, body mass index, duration of marriage, parity and history of abortion. Routine laboratory investigations included hormonal status like serum follicle stimulating hormone, serum luteinizing hormone, serum prolactin level, blood sugar 2 hours after 75 g glucose load and serum thyroid stimulating hormone. Specific investigations included ultrasonography of lower abdomen including both ovaries and fallopian tubes. Collected data was compiled and analyzed using computerbased software (SPSS).

\section{Results:}

Fifty women suffering from PCOS with hyperprolactinaemia and hypothyroidism were recruited for evaluation as other associated factors for subfertility. Table I shows that the age range was 2038 years (mean \pm SD 26.78 \pm 3.83 years) and BMI range was 17.70 $33.20 \mathrm{~kg} / \mathrm{m}^{2}$ (mean \pm SD $\left.25.63 \pm 3.38 \mathrm{~kg} / \mathrm{m}^{2}\right)$. Menstrual cycle was regular in 12 (24\%) and irregular in 38 (76\%) patients, 46 (92\%) were nulliparous and 4 (8\%) were primiparous. History of abortion was present in 6 (12\%) and absent in 44 (88\%) patients. In 28 (56\%) patients duration of marriage $\leq 5$ years, in 19 (38\%) was 510 years and more than 10 years in $3(6 \%)$ (mean \pm SD 5.77 \pm 3.26 , range 116 years).

\section{Table I}

Characteristics of the study women $(n=50)$

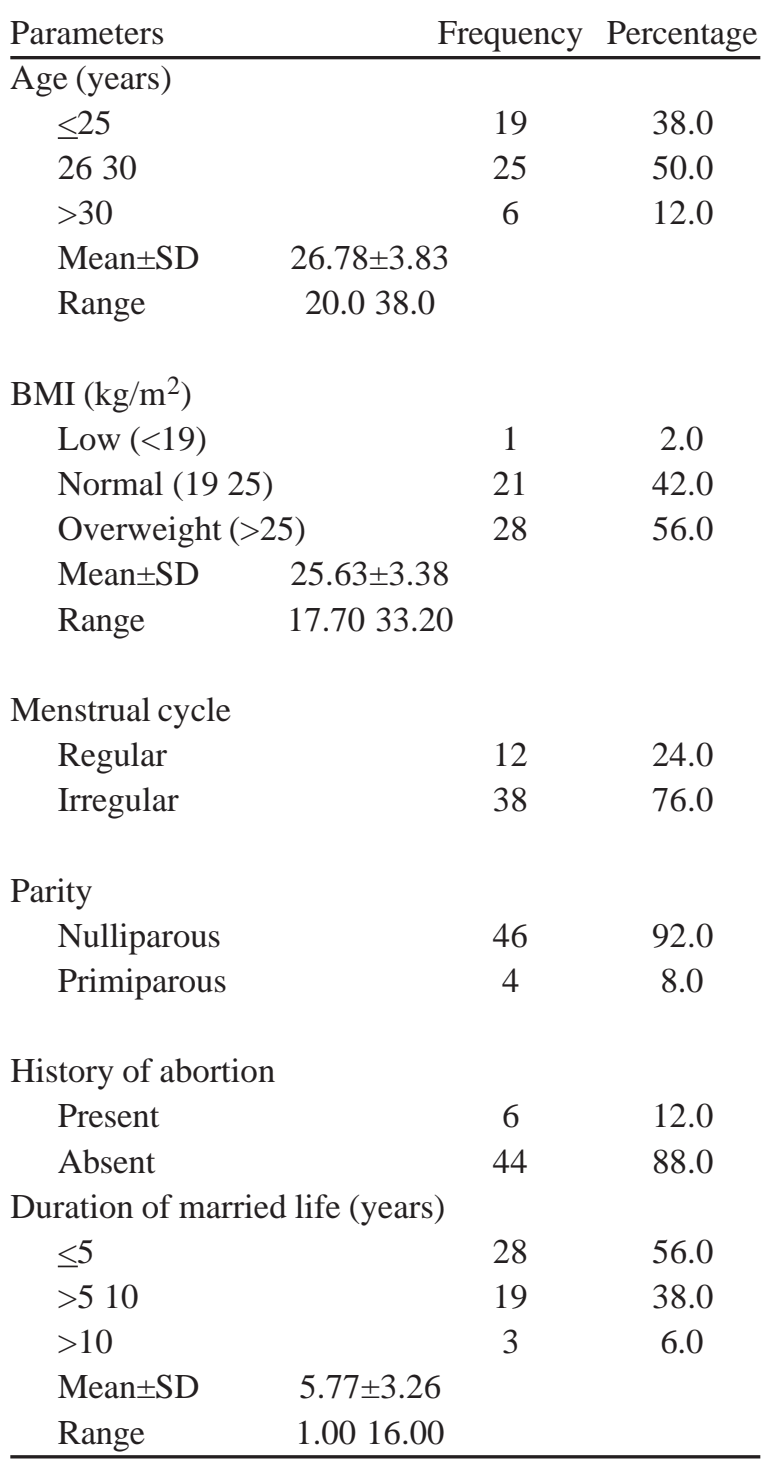

Table II shows laboratory investigation findings. Serum FSH was normal (1 $10 \mathrm{mIU} / \mathrm{ml})$ in all 50 (100\%) patients (mean \pm SD 3.76 \pm 1.23 , range $1.507 .00 \mathrm{mIU} / \mathrm{ml}$ ). Serum LH was normal (1 $10 \mathrm{mIU} / \mathrm{ml}$ ) in 13 (26\%) and raised (>10 $\mathrm{mIU} / \mathrm{ml})$ in 37 (74\%) patients (mean \pm SD $12.50 \pm 4.33$, range $6.70-27.00 \mathrm{mIU} / \mathrm{ml})$. Serum prolactin was normal $(1.9-25.0 \mathrm{ng} / \mathrm{ml})$ in $20(40 \%)$ and raised $(>25 \mathrm{ng} / \mathrm{ml})$ in 30 (60\%) patients (mean \pm SD 64.98 \pm 135.48 , range 7.20-930.80 ng/ml). Serum TSH was normal $(0.4-4.0 \mu \mathrm{U} / \mathrm{ml})$ in $13(26 \%)$ and raised $(>4.0$ $\mu \mathrm{U} / \mathrm{ml}$ ) in 37 (74\%) patients (mean \pm SD 9.23 \pm 5.84 , 
range $1.8025 .80 \mu \mathrm{IU} / \mathrm{ml})$. Serum level of blood glucose 2 hours after 75 g glucose load was normal $(<7.8 \mathrm{mmol} /$ $\mathrm{L})$ in $30(60 \%)$ and raised $(\geq 7.8 \mathrm{mmol} / \mathrm{L})$ in $20(40 \%)$ patients (mean \pm SD 7.60 \pm 1.77 , range $4.3013 .40 \mathrm{mmol} /$ L). Ultrasonogram finding of lower abdomen was normal in 13 (26\%) and abnormal (polycystic ovaries) in 37 (74\%) patients.

\section{Table-II}

Investigation findings $(n=50)$

\begin{tabular}{|c|c|c|}
\hline \multirow{2}{*}{$\begin{array}{l}\text { Parameters } \\
\text { Serum FSH (mIU/ml) }\end{array}$} & Frequency & \multirow[t]{2}{*}{ Percentage } \\
\hline & & \\
\hline Normal (1.0 10.0) & 50 & 100.0 \\
\hline Raised (>10.0) & 0 & 0 \\
\hline Mean \pm SD & $3.76 \pm 1.23$ & \\
\hline Range & 1.507 .00 & \\
\hline \multicolumn{3}{|c|}{ Serum LH (mIU/ml) } \\
\hline Normal (1.0 10.0) & 13 & 26.0 \\
\hline Raised (>10.0) & 37 & 74.0 \\
\hline Mean \pm SD & $12.50 \pm 4.33$ & \\
\hline Range & 6.7027 .00 & \\
\hline \multicolumn{3}{|c|}{ Serum prolactin (ng/ml) } \\
\hline Normal (1.9 25.0) & 20 & 40.0 \\
\hline Raised (>25.0) & 30 & 60.0 \\
\hline Mean \pm SD & $4.98 \pm 135.48$ & \\
\hline Range $\quad 7$. & 7.20930 .80 & \\
\hline \multicolumn{3}{|c|}{ Serum TSH (ìIU/ml) } \\
\hline Normal 0.44 .0 & 13 & 26.0 \\
\hline Raised (>4.0) & 37 & 74.0 \\
\hline Mean \pm SD & $9.23 \pm 5.84$ & \\
\hline Range $\quad 1$ & 1.8025 .80 & \\
\hline \multicolumn{3}{|c|}{ Blood sugar 2HAB (mmol/L) } \\
\hline Normal $(<7.8)$ & 30 & 60.0 \\
\hline Raised (37.8) & 20 & 40.0 \\
\hline Mean \pm SD & $7.60 \pm 1.77$ & \\
\hline Range $\quad 4$ & 4.3013 .40 & \\
\hline \multicolumn{3}{|c|}{ USG of lower abdomen } \\
\hline Normal & 13 & 26.00 \\
\hline Abnormal & 37 & 74.0 \\
\hline
\end{tabular}

\section{Discussion:}

The present study was designed to investigate the associated causes of subfertility in PCOS patients. In this observational study, serum FSH was normal in all 50 (100\%) patients. Raised level of serum prolactin was found in 30 (60\%), serum LH in 37 (74\%) and serum
TSH in 37 (74\%) patients. Our study population included both primary and secondary subfertile women.

In our study, we observed that the prolactin level was high (mean \pm SD $64.98 \pm 135.48 \mathrm{ng} / \mathrm{ml}$ ) in $60 \%$ cases, which is concordant with Kalsum and Jalali, where $69.51 \%$ of subfertile women suffered from hyperprolactinaemia ${ }^{6}$. Nizam et al. also showed that hyperprolactinaemia is a major cause of subfertility, and treatment with drugs which lowers prolactin level showed that $24 \%$ infertile women became pregnant ${ }^{7}$. This finding is consistent with ours.

In our study, increased level of serum TSH (>4 ìIU/ml, mean \pm SD 9.23 $\pm 5.84 \mathrm{iIU} / \mathrm{ml}$ ) was found in $74 \%$ women. This is an indication of subclinical hypothyroidism. In a study by Joshi et al. (1993), reproductive history was related chronologically to symptoms and signs of thyroid dysfunction. Reproductive failure (infertility, pregnancy wastage, lactation failure) occurred in $45 \%$ of cases with menstrual abnormality, which was antecedent to other clinical features by a variable period of two months to ten years. Reproductive failure also precedes thyroid dysfunction which is concordant with the present study. This finding is also consistent with the study by Hollowell et al. (2002), who found women with both clinical and subclinical hypothyroidism in early pregnancy and found miscarriage rate was higher in both groups and treatment with hormones could reduce the miscarriage risk ${ }^{8}$. These findings are also consistent with the findings by Trokoudes et al. who found subclinical hypothyroidism is associated with ovulatory dysfunction and adverse pregnancy outcome ${ }^{9}$.

Present study is also similar to a case control study by Joshi et al. (1993), who found 34\% subclinical thyroidism was associated with infertility and pregnancy wastage. Elder (2007) in his cohort study found 20.5\% infertile women had associated subclinical hypothyroidism ${ }^{10}$. Yasmin et al. showed an association between subclinical hypothyroidism and infertility. One quarter (25\%) of the infertile group had subclinical level of serum TSH ( $>5 \mathrm{mIU} / \mathrm{L})$ compared to $10 \%$ of the control group $(\mathrm{P}<0.05)$. Computation of risk ratio revealed that the infertile group had 3 times (1.3 6.6) higher risk of being subclinically hypothyroid than that of the control group $(\mathrm{P}<0.01)^{11}$.

\section{Conclusion:}

The present study was carried out to find out an association of other factors for subfertility in women 
suffering from PCOS. In this study we found that hyperprolactinaemia and subclinical hypothyroidism were the other associated causes of subfertility. In the light of our findings it is recommended to undertake further large scale study to find out whether therapy with thyroxine and drugs for decreasing levels of prolactin increases the fertility rate in women suffering from PCOS.

\section{References:}

1. Ehrmann DA. Polycystic ovary syndrome. N Engl J Med 2005; 352:1223 1226.

2. Balen AH. Polycystic ovary syndrome and secondary amenorrhoea. In: Edmonds DK, editor. Dewhurst's textbook of obstetrics and gynaecology for the postgraduates. 7th ed. Oxford: Blackwell Scientific Publications, 2007, 377398.

3. Zawadski JK, Dunaif A. Diagnostic criteria for polycystic ovary syndrome: towards a rational approach. In: Dunaif A, Givens JR, Haseltine F, editors. Polycystic ovary syndrome. Oxford: Blackwell Scientific Publications, 1992: 377-384.

4. The Rotterdam ESHRE/ASRM Sponsored PCOS consensus workshop group. Revised 2003 consensus on diagnostic criteria and long term health risks related to polycystic ovary syndrome (PCOS). Hum Reprod 2004; 19:41-47.
5. Balen AH, Conway GS, Ealtsas G et al. Polycystic ovary syndrome: the spectrum of the disorder in 1741 patients. Human Reprod 1995; 10:2107-2111.

6. Kalsum A, Jalali S. Role of hyperprolactinemia in fertility. Pak J Med Res 2002; 41:1-5.

7. Nizam K, Memon N, Devrajani BR. Outcome of treatment with lisuride in hyperprolactinemic infertile women. J Liaquat Univ Med Hlth Sci 2008; 120-123.

8. Hollowell JG, Staehling NW, Flanders WD et al. Serum TSH, $\mathrm{T}_{4}$ and thyroid antibodies in the United States population (1988 to 1994). National Health and Nutrition Examination Survey (NHANES III). J Clin Endocrinol Metab 2002; 87: 489-499.

9. Trokoudes, KMA, Skordis NB, Picolos MKC. Reproductive endocrinology: infertility and thyroid disorders. Curr Opin Obstet Gynecol 2006; 18:446-451.

10. Eldar Geva J, Shoham M, Rosler A, et al. Subclinical hypothyroidism in infertile women: the importance of continuous monitoring and the role of thyrotrophin releasing hormone stimulation test. Gynecol Endocrinol 2007; 23: 332-337.

11. Yasmin F, Ava NN, Jahan K, et al. Association between subclinical hypothyroidism and infertility. Bangladesh J Urol 2008; 11:47-53. 